\title{
Penerapan Automatic Transfer Switch Pada Sistem Irigasi Di Desa Rejosari Kabupaten Madiun
}

\author{
Yuli Prasetyo ${ }^{1}$, Budi Triyono ${ }^{2}$, Hanifah N.K. ${ }^{2}$, R. Jasa Kusumo ${ }^{2}$, Nur Asyik H. ${ }^{2}$, Wisnu Muchsin ${ }^{2}$ \\ ${ }^{1}$ Prodi Perkeretaapian, Politeknik Negeri Madiun, Jl. Serayu No. 84, Madiun, 63133 \\ ${ }^{2}$ Prodi Teknik Listrik, Politeknik Negeri Madiun, Jl. Serayu No. 84, Madiun, 63133 \\ E-mail: yuliprasetyo2224@pnm.ac.id
}

\begin{abstract}
Abstrak - Desa Rejosari memiliki potensi yang sangat besar yaitu terdapat banyak persawahan yang melimpah di sekitar pemukiman. Desa Rejosari terletak di Kecamatan Kebonsari Kabupaten Madiun. Petani di desa Kebonsari telah menggunakan pompa air yang digunakan pada sistem irigasi sawah. Namun, sampai saat ini banyak petani yang masih menggunakan PLN sebagai sumber utama dalam menjalankan motor listrik untuk sistem irigasi. Sehingga para petani sering mengalami pemadaman listrik akibat kekurangan daya listrik. Kegiatan pengabdian kepada masyarakat melalui program kemitraan bagi kelompok tani di Desa Rejosari Kecamatan Kebonsari, Kabupaten Madiun dititik beratkan pada pembuatan panel Automatic Transfer Switch (ATS) untuk mengubah switch sumber energi listrik dari PLN ke sumber energi matahari dari panel surya. Panel ATS ini berisi switch yang dapat mengganti sumber energi listrik pada motor listrik yang semula dari PLN menjadi sumber energi dari Panel Surya. Harapannya dengan program pengabdian kepada masyarakat ini kelompok tani dapat memperoleh energi listrik untuk menyalakan sistem irigasi dan tidak bergantung pada PLN. PKM ini juga dapat memperkecil biaya tarif listrik yang dikeluarkan oleh petani.
\end{abstract}

Kata Kunci — Pertanian, Automatic Transfer Switch, Panel surya, Sumber energi mandiri

\begin{abstract}
Rejosari Village has enormous potential, namely there are many abundant rice fields around the settlement. Rejosari Village is located in Kebonsari District, Madiun Regency. Farmers in Kebonsari village have used a water pump that is used in the rice field irrigation system. However, until now many farmers still use PLN as the main source in running electric motors for irrigation systems. So that farmers often experience power outages due to lack of electrical power. Community service activities through a partnership program for farmer groups in Rejosari Village, Kebonsari District, Madiun Regency are focused on making Automatic Transfer Switch (ATS) panels to convert electrical energy source switches from PLN to sources of solar energy from solar panels. This ATS panel contains a switch that can replace the source of electrical energy in an electric motor that was originally from PLN into an energy source from the Solar Panel. The hope is that with this community service program, farmer groups can obtain electrical energy to power the irrigation system and not depend on PLN. This PKM can also reduce the cost of electricity rates incurred by farmers.
\end{abstract}

Keywords - Agriculture, Automatic Transfer Switch, Solar Panel, Independent energy sources

\section{PENDAHULUAN}

Potensi Desa Rejosari Kabupaten Madiun adalah banyaknya persawahan. Hampir sebagian besar penduduk di desa Rejosari bekerja sebagai petani. Lahan pertanian di desa rejosari memiliki saluran irigasi yang berupa selokan kecil. Sumber air pada selokan kecil ini berasal dari sumur yang dipompa menggunakan motor pompa. Motor pompa ini membutuhkan listrik untuk dapat bekerja [1].

Banyak petani yang masih menggunakan listrik PLN sebagai sumber energi listrik untuk menyalakan pompa air. Penggunaan sumber energy listrik dari PLN untuk pompa air ini banyak menimbulkan masalah. Salah satu masalah yang sering timbul adalah pemadaman listrik. Pemadaman listrik ini disebabkan karena kelebihan daya listrik sehingga motor pompa tidak dapat dialiri arus listrik dari PLN .
Oleh karena itu untuk mengatasi permasalahan ini diperlukan sebuah teknologi terbarukan untuk sumber energi matahari [2],[3]. Penerapan Automatic Transfer Switch (ATS) ini sangat tepat digunakan untuk mengatasi permasalahan [4],[5],[6]. Penggunaan ATS dapat memberi pilihan kepada para petani di desa Rejosari untuk tidak selalu menggunakan sumber listrik PLN. Diharapkan dengan adanya penerapan ATS ini dapat membantu para petani dalam hal tidak bergantung lagi pada sumber listrik PLN. Penerapan ATS ini juga dapat memberikan keamanan bagi para petani dari bahaya tersengat arus listrik akibat arus bocor pada pompa air. 


\section{ANALISIS SITUASI}

Kegiatan PKM ini dilaksanakan di mitra petani desa Rejosari Kabupaten Madiun. Desa Rejosari dipilih karena memiliki persawahan dengan sistem irigasi menggunakan pompa air yang bertenaga listrik. Setelah dilakukan diskusi dengan kelompok petani desa rejosari didapatkan beberapa permasalahan. Permasalahan pada mitra dapat dirinci sebagai berikut:

a. Sistem irigasi masih menggunakan PLN sebagai sumber utama pompa air.

b. Kebanyakan petani di desa Rejosari menggunakan pompa air untuk sistem irigasi.

c. Sering terjadi pemadaman listrik akibat kekurangan daya untuk menyalakan pompa air.

Dari rangkuman seluruh permasalahan tersebut, maka pokok persoalan yang dihadapi mitra adalah memerlukan sumber listrik pengganti PLN untuk menyalakan pompa air. Untuk itulah rencana kegiatan yang diusulkan dalam pelaksanaan program PKM ini lebih menekankan pada teknologi automatic transfer switch. Teknologi ATS ini dapat memberikan sumber energy lain selain PLN, sehingga pompa air masih dapat berfungsi jika tidak menggunakan sumber PLN. Kondisi pompa air di desa Rejosari harus dicek terlebih dahulu seperti pada gambar 1 .

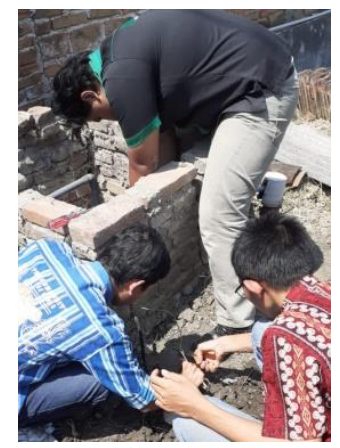

Gambar 1. Pengecekan Kondisi Pompa Air

\section{METODE}

Metode pelaksanaan PKM ini adalah :

a. Tahapan Pra PKM

Pada tahapan ini adalah melakukan wawancara, observasi, dan konseling dengan kelompok tani berkaitan dengan permasalahan yang dihadapi. Tahap ini mencari latar belakang dan permasalahan yang ada pada mitra dan solusi untuk mengatasi permasalahan tersebut.

b. Tahapan Persiapan

Pada tahapan ini melakukan pengadaan peralatan dan persiapan tempat dan sarana, dan pemberitahuan ke mitra tentang teknis pelaksanaan PKM.

c. Tahapan Pelaksanaan

Pada tahapan ini adalah pelaksanaan penerapan panel surya sesuai dengan jadwal yang telah ditetapkan.

\section{HASIL DAN PEMBAHASAN}

Kegiatan pengabdian kepada masyarakat melalui program kemitraan bagi masyarakat di kelompok tani Desa Rejosari Kecamatan Kebonsari, Kabupaten Madiun dititik beratkan pada pada pembuatan panel ATS untuk mengubah switch sumber energi listrik dari PLN dengan sumber energi matahari dari panel surya. Harapannya dengan program pengabdian kepada masyarakat ini kelompok tani dapat memperoleh energi listrik untuk menyalakan sistem irigasi dan tidak bergantung pada PLN.

Berikut ini luaran kegiatan PKM yang diinginkan.

a. Penerapan energi terbarukan yang mudah dan murah untuk sumber energi listrik.

b. Tidak bergantung pada sumber listrik PLN.

c. Tidak terjadi pemadaman listrik

Pelaksanaan PKM ini dimulai dengan pembuatan panel ATS untuk diterapkan pada pompa air. Kemudian pembuatan kerangka panel surya dan pemasangan kerangka panel surya di desa Rejosari. Pembuatan panel ATS seperti pada gambar 2. Pemasangan panel surya di tempat PKM seperti pada gambar 3.

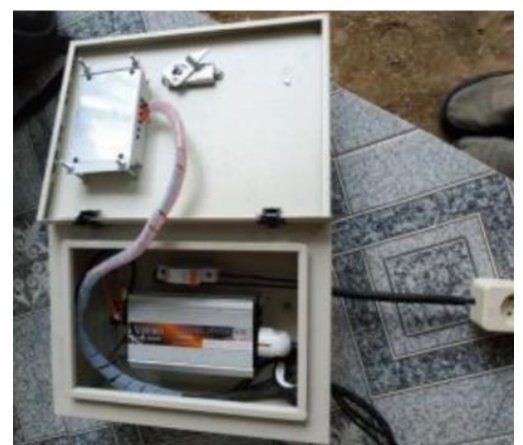

Gambar 2. Pembuatan Panel ATS

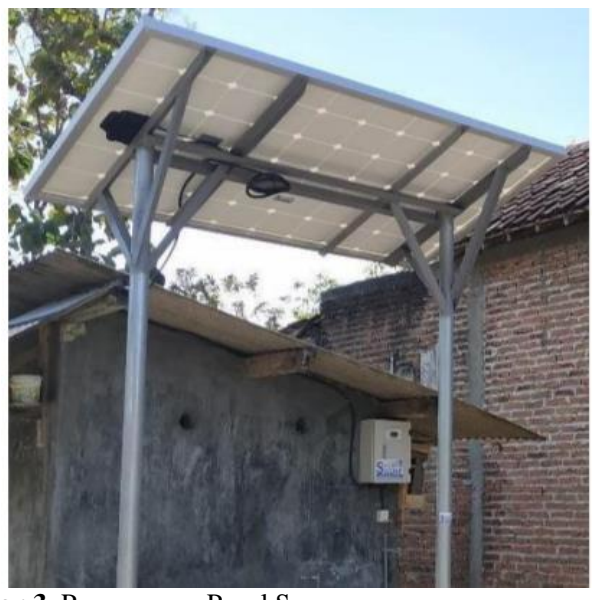

Gambar 3. Pemasangan Panel Surya 
Setelah selesai pemasangan kerangka panel surya dan pembuatan panel ATS adalah melakukan pengukuran tegangan keluaran panel surya. Hal ini diperlukan untuk mengetahui panel surya dapat mensuplai pompa air atau tidak. Pengecekan keluaran panel Surya seperti pada gambar 4. Tegangan keluaran panel surya sudah sesuai dengan yang diharapkan. Kemudian dilakukan penyambungan panel ATS dengan motor pompa air. Setelah itu dilakukan pengujian agar mengetahui kondisi sistem ATS. Sumber listrik dari panel surya dapat bekerja dengan baik untuk menyalakan pompa air. Begitu pula sumber listrik dari PLN. Perpindahan sumber listrik dari PLN ke panel surya atau dari panel surya ke PLN juga dapat bekerja dengan baik.

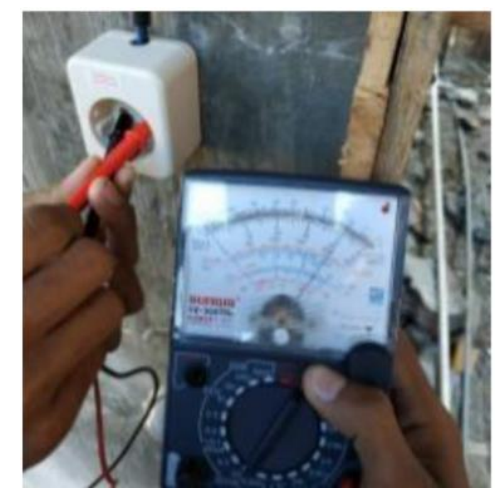

Gambar 4. Uji Coba tegangan output panel surya

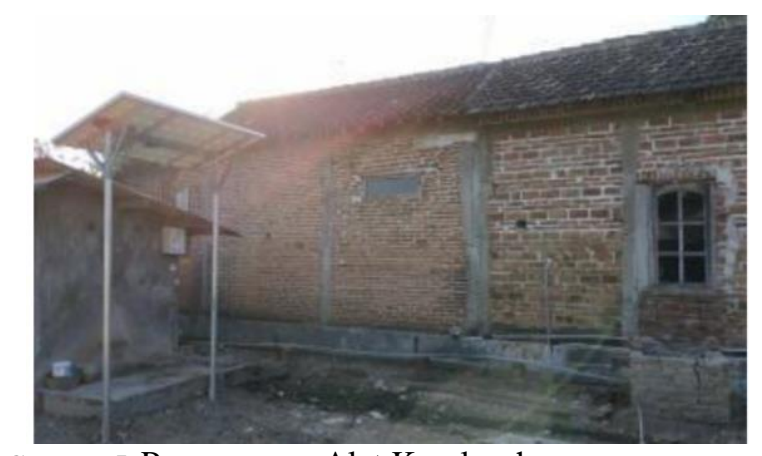

Gambar 5. Pemasangan Alat Keseluruhan

Tabel 1. Kondisi mitra sebelum dan sesudah pelaksanaan PKM

\begin{tabular}{ll}
\hline \multicolumn{1}{c}{ Sebelum PKM } & \multicolumn{1}{c}{ Setelah PKM } \\
\hline $\begin{array}{l}\text { Mitra masih menggunakan } \\
\text { sumber listrik PLN }\end{array}$ & $\begin{array}{l}\text { Mitra memiliki sumber listrik } \\
\text { dari panel surya }\end{array}$ \\
$\begin{array}{l}\text { Mitra belum memiliki } \\
\text { pemahaman tentang } \\
\text { penerapan teknologi panel } \\
\text { surya }\end{array}$ & $\begin{array}{l}\text { Mitra memiliki pemahaman } \\
\text { dan dapat mengoperasikan } \\
\text { panel surya }\end{array}$ \\
$\begin{array}{l}\text { Mitra sering mengalami } \\
\text { pemadaman listrik }\end{array}$ & $\begin{array}{l}\text { Mitra dapat menggunakan } \\
\text { panel surya jika listrik dari } \\
\text { PLN terputus }\end{array}$ \\
\hline
\end{tabular}

Setelah pemasangan alat selesai kemudian melakukan pendampingan alat agar para petani dapat mengoperasikan sistem panel ATS dengan baik. Hasil evaluasi ini adalah pembinaan kepada mitra agar jika terjadi masalah atau kerusakan pada alat dapat segera diperbaiki sendiri oleh mitra. Tabel 1 menjelaskan tentang kondisi mitra sebelum dan sesudah PKM. Hasil PKM ini juga terlihat dari dapat beroperasinya penyiraman bibit tanaman menggunakan pompa air bertenaga panel surya. Penyiraman bibit tanaman menggunakan pompa air bertenaga panel surya seperti pada gambar 6 .

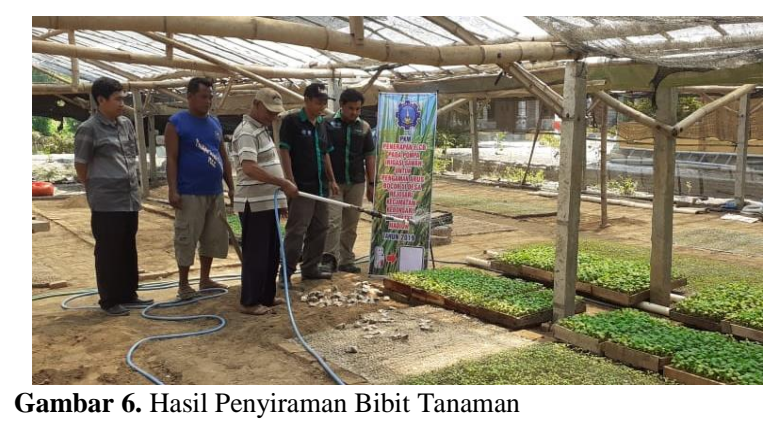

\section{KESIMPULAN}

Para petani di desa Rejosari Kabupaten Madiun tidak khawatir lagi akan pemadaman listrik dikarenakan sudah ada sumber listrik dari panel surya. Para petani juga tidak bergantung lagi pada sumber listrik PLN karena sebagian besar dapat dialiri listrik dari panel surya.

\section{UCAPAN TERIMA KASIH}

Ucapan terimakasih diberikan kepada Politeknik Negeri Madiun yang telah memberikan dukungan pendanaan selama kegiatan Program Kemitraan Masyarakat tahun 2020 ini berlangsung.

\section{DAFTAR PUSTAKA}

[1] B. Triyono and Y. Prasetyo, 2019. Penerapan ELCB Pada Pompa Irigasi Sawah Untuk Pengaman Arus Bocor Di Desa Rejosari Madiun," J-Adimas : J. Pengabdi. Kpd. Masy., vol. 7, p. 4.

[2] B. H. Purwoto, 2018. Efisiensi Penggunaan Panel Surya Sebagai Sumber Energi Alternatif, Emit. J. Tek. Elektro, vol. 18, no. 01, pp. 10-14, doi: 10.23917/emitor.v18i01.6251.

[3] Y. Prasetyo, B. Triyono, and A. C. Arifin, 2019. Optimalisasi Daya Output Dual Axis Solar Tracker Dengan Metode Umbrella System, Jurnal Geuthee, vol. 02, no. 02, p. 8. 
[4] A. Julisman, I. D. Sara, and R. H. Siregar, 2017. Prototipe Pemanfaatan Panel Surya Sebagai Sumber Energi Pada Sistem Otomasi Atap Stadion Bola, KIELEKTRO: Jurnal Online Teknik Elektro, 2(1) p. 35-42.
[5] E. Susanto, 2013. Automatic Transfer Switch (Suatu Tinjauan), Jurnal Teknik Elektro, vol. 5, no. 1 , p. $18-21$.

[6] D. Hendarto, 2015. Rancang Bangun Panel Automatic Transfer Switch (Ats) Dan Automatic Main Failure (Amf) Kapasitas $66 \mathrm{Kva}$, Jurnal Teknik Elektro dan Sains 2 (1) p. 21-32. 